\title{
Hubungan antara Jenis Sedimen Pasir dan Kandungan Bahan Organik di Pantai Kartini, Jepara, Jawa Tengah
}

\author{
Gadisza Asmara Yudha*, Chrisna Adhi Suryono, Adi Santoso \\ Departemen IImu Kelautan, Fakultas Perikanan dan IImu Kelautan Universitas Diponegoro \\ JI. Prof. H. Soedarto S.H, Tembalang Semarang, Jawa Tengah 50275 Indonesia \\ *Corresponding author, e-mail : gadiszaay@gmail.com
}

\begin{abstract}
ABSTRAK: Pantai Kartini merupakan salah satu kawasan wisata di Kabupaten Jepara. Berbagai aktifitas masyarakat serta infrastruktur perairan menjadi kebutuhan yang sangat krusial dengan letak Pantai Kartini. Adanya aktivitas dan bangunan dapat menyebabkan perubahan sebaran ukuran butir dan kandungan bahan organik. Penelitian ini memiliki tujuan untuk mengetahui jenis dan klasifikasi sedimen serta jumlah kandungan bahan organik yang terdapat dalam sedimen di Pantai Kartini, Jepara. Pengambilan data pada penelitian ini yaitu pengambilan data primer yang berupa sampel sedimen dengan menggunakan sediment core. Dilanjutkan dengan analisis sampel sedimen dan analisis kandungan bahan organik. Hasil penelitian menunjukkan bahwa di perairan Pantai Kartini, Jepara memiliki jenis sedimen pasir (sand) dimana nilai ukuran butir tersebut berkisar dari $81-96 \%$, yang mana pada Stasiun 1 rata-rata sebesar 91,6-96\%, Stasiun 2 rata-rata sebesar 93,5-96,9\%, dan Stasiun 3 rata-rata sebesar 81,4-92,9\%. Sedangkan, Kandungan Bahan Organik yang terdapat di perairan tersebut memiliki konsentrasi berkisar dari 5-14\% yang termasuk dalam kriteria rendahsedang, dimana pada Stasiun 1 rata-rata sebesar 10,9-13,3\%, Stasiun 2 rata-rata sebesar $5,92-10,18 \%$, dan Stasiun 3 rata-rata sebesar 7,7-14\%.
\end{abstract}

Kata kunci : Sedimen; Bahan Organik; Pantai Kartini; Jepara

\section{Relationship between Types of Sand Sediment and Organic Material Content on Kartini Beach, Jepara, Central Java}

\begin{abstract}
Kartini Beach is one of the tourist areas in Jepara Regency. Various community activities and water infrastructure have become crucial needs in Kartini Beach. The existence of activities and buildings can cause changes in the distribution of grain size and content of organic matter. This study aims to determine the type and classification of sediments and the amount of organic matter content contained in sediments in Kartini Beach, Jepara. Data collection in this study is primary data collection in the form of sediment samples using sediment cores. Followed by analysis of sediment samples and analysis of organic matter content. The results showed that in Kartini Coast waters, Jepara had a sand sediment type where the grain size values ranged from 81-96\%, which at Station 1 averaged 91,6-96\%, Station 2 on average amounted to 93,5-96,9\%, and Station 3 averaged 81,4-92,9\%. Meanwhile, the content of organic matter contained in these waters has concentrations ranging from $5-14 \%$ which are included in the criteria of low-moderate, where at Station 1 an average of 10,9-13,3\%, Station 2 an average of 5,92-10,18\%, and Station 3 averaging $7,7-14 \%$.
\end{abstract}

Keywords: Sedimen; Organic Matter; Kartini Beach; Jepara

\section{PENDAHULUAN}

Pantai merupakan bentang alam yang selalu mengalami perubahan, hal ini disebabkan oleh proses yang berlangsung didalamnya yaitu arus dan gelombang yang merupakan proses yang berasal dari laut dan aliran sungai yang membawa sedimen yang merupakan proses dari daratan (Handoyo dan Agus, 2015). Pantai Kartini merupakan salah satu kawasan wisata yang ternama di 
Kabupaten Jepara dengan sebagian besar penduduknya terpusat di daerah tepi pantai. Berbagai aktifitas masyarakat serta infrastruktur perairan menjadi kebutuhan yang sangat krusial dengan letak Pantai Kartini yang berbatasan langsung dengan Laut Jawa (Rahmawati et al., 2015).

Banyaknya bangunan dan aktivitas masyarakat di sekitar pantai maka pada Pantai Kartini terdapat muatan yang terbawa oleh sumber-sumber tersebut yang beranekaragam di pesisir maupun perairan pantai. Muatan yang terbawa sampai ke pantai dan sekitarnya akan terendap, hal ini menjadi suatu tolak ukur kesuburan daerah pantai tersebut. Muatan-muatan yang berasal dari berbagai sumber lalu mengendap itu yang disebut dengan sedimentasi. Dengan adanya sedimentasi, maka akan tercipta sedimen. Segala sesuatu yang terbawa oleh pergerakan air laut tentunya akan berujung pada zona ini. Sesuatu yang terbawa air laut itu biasanya adalah sedimen. Sedimen pada umumnya berupa partikel yang berasal dari cangkang, sisa kerangka organisme maupun pembongkaran bebatuan (Bayhaqi dan Caesar, 2015). Sedimen juga berasal dari pecahan-pecahan material yang umumnya terdiri atas uraian batu-batuan secara fisis dan secara kimia. Partikel seperti ini mempunyai ukuran dari yang besar (boulder) sampai yang sangat halus (koloid), dan beragam bentuk dari bulat, lonjong sampai persegi (Usman, 2014). Material sedimen akan terendapkan oleh proses mekanik arus yang berasal dari sungai dan atau oleh arus laut. Sedimentasi di suatu lingkungan perairan terjadi karena terdapat suplai muatan sedimen yang tinggi di lingkungan tersebut (Triapriyasen et al., 2016).

Muara sungai sangat kaya akan bahan organik yang disebabkan partikel yang mengendap di air laut maupun air tawar pada umumnya mengandung bahan organik (Nybakken, 1992). Kandungan bahan organik dalam sedimen sangat berhubungan dengan jenis atau tekstur sedimen, tekstur yang berbeda mempunyai kandungan bahan organik yang berbeda pula (Choirudin et al., 2014). Tingginya bahan organik yang masuk ke perairan berasal dari peningkatan aktivitas di daratan seperti pemupukan di sawah dan tambak, budidaya, industri dan aktivitas rumah tangga yang masuk ke dalam perairan (Mushthofa et al., 2014). Bahan organik merupakan pencemar yang paling umum di jumpai dan dampak yang dtimbulkannya tidak langsung. Dampak yang ditimbulkan oleh bahan organik adalah menurunkan kandungan oksigen terlarut dan terjadi proses eutrofikasi (proses bertumbuh kembangnya organisme perairan karena kesuburan yang meningkat dan biasanya mempunyai dampak negatif terhadap ikan) (Manengkey, 2010).

Sehubungan dengan adanya proses sedimentasi dan masukan muatan yang masuk di lingkungan Pantai Kartini, maka penelitian ini bertujuan mencari hubungan sedimen pasir dan kandungan bahan organik di Pantai Kartini, Jepara.

\section{MATERI DAN METODE}

Penelitian ini berlokasi di Pantai Kartini, Jepara. Dimana pengambilan sampel dilakukan pada tanggal 24 Oktober 2019 dan pengolahan sampel sedimen dilakukan pada bulan Desember 2019 hingga Februari 2020. Pengambilan sampel dilakukan di kawasan yang terdapat aktivitas nelayan, pelabuhan, tambak, rumah tangga, dan bangunan sekitar pantai. Pengambilan berada di 3 tempat (stasiun), yaitu Muara Sungai TPI, Muara Sungai LPWP, dan Muara Sungai BBPBAP Lama dengan masing-masing 3 titik disetiap stasiun (Gambar 1).

Pengambilan sampel sedimen menggunakan sediment core. Lokasi pengambilan berada di 3 tempat (stasiun), yaitu Muara Sungai TPI, Muara Sungai LPWP, dan Muara Sungai BBPBAP Lama dengan 3 titik yang berbeda kedalaman disetiap stasiun. Pengambilan sampel sedimen dengan sediment core yaitu menggunakan pipa besi sepanjang $1 \mathrm{~m}$ yang ditancapkan ke permukaan dasar perairan hingga kedalaman tertentu. Apabila telah mencapai kedalaman yang ditentukan kemudian pipa ujungnya ditutup agar udara dihambat lalu ditarik. Sampel sedimen dimasukkan kedalam wadah plastik (ziplock) yang telah diberi label.

Sampel sedimen dikeringkan selama 1 minggu ( 7 hari) dibawah sinar matahari secara langsung agar sampel kering merata sehingga tidak menempel. Wadah yang dipakai dalam proses pengeringan adalah alumunium foil, diduga akan mempercepat proses pengeringan itu sendiri karena menyerap panas.

Analisis sampel sedimen dilakukan di Laboratorium Geologi, Fakultas Perikanan dan IImu Kelautan, Universitas Diponegoro Semarang. Sampel sedimen kemudian diklasifikan sesuai 
dengan ukuran hasil Analisis Granulometri. Analisis granulometri yang dilakukan berupa pengayakan sampel menggunakan sieve shaker dan pemipetan. Sampel sebanyak $200 \mathrm{gr}$ dimasukkan ke dalam sieve shaker untuk dipisahkan bedasarkan ukuran butiran yang sudah ditentukan, yaitu $2 \mathrm{~mm}, 0,5 \mathrm{~mm}, 0,3 \mathrm{~mm}, 0,15 \mathrm{~mm}$, dan 0,0625 mm. Tahap pemipetan menggunakan sampel yang berukuran $0,0625 \mathrm{~mm}$. Setelah pemipetan, sampel diklasifikasikan sesuai dengan Skala Wentworth dan dilakukan penamaan menggunakan segitiga Shepard (Gambar 2) (Triapriyasen et al., 2016).

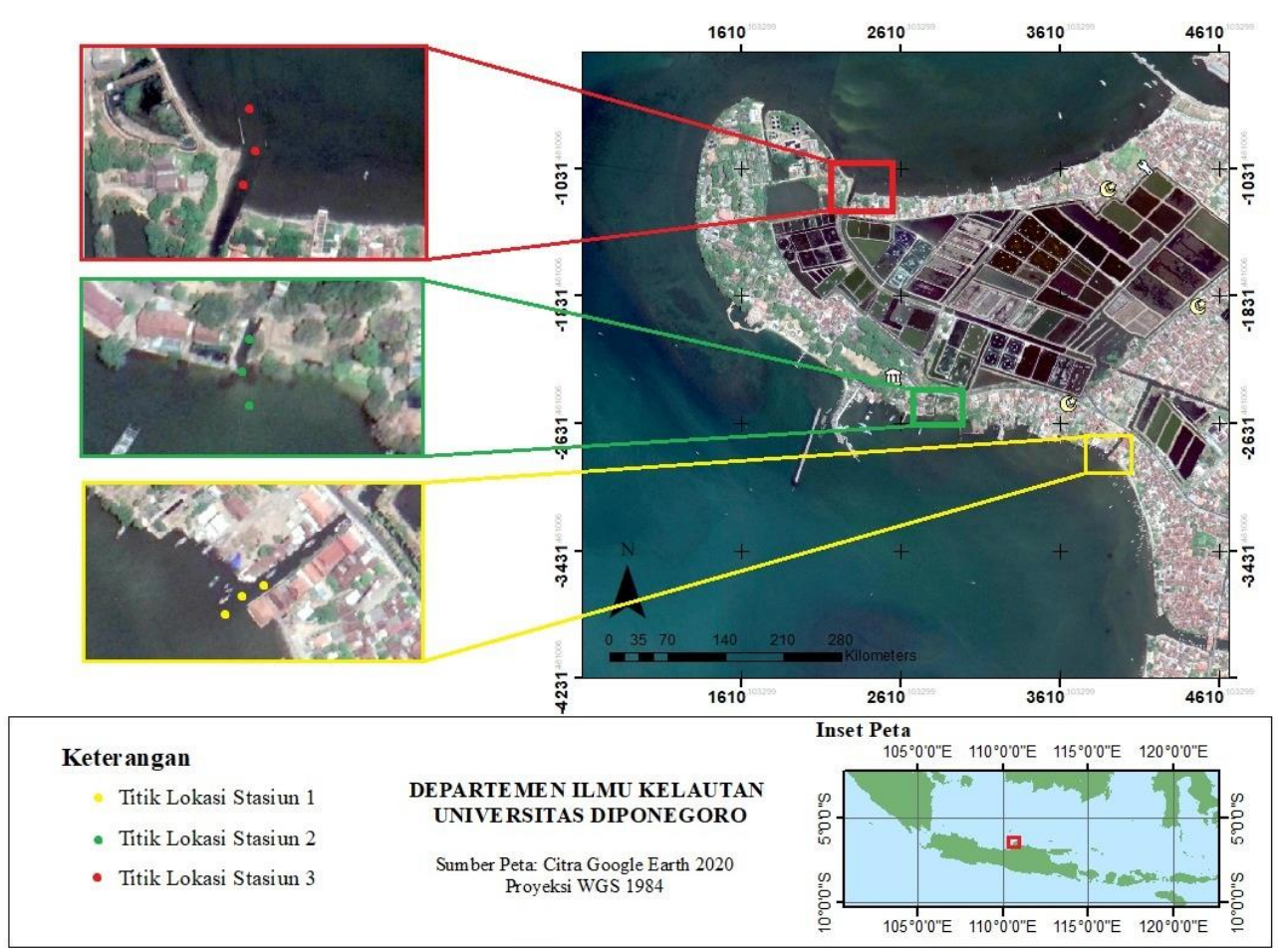

Gambar 1. Lokasi pengambilan sample di Jepara

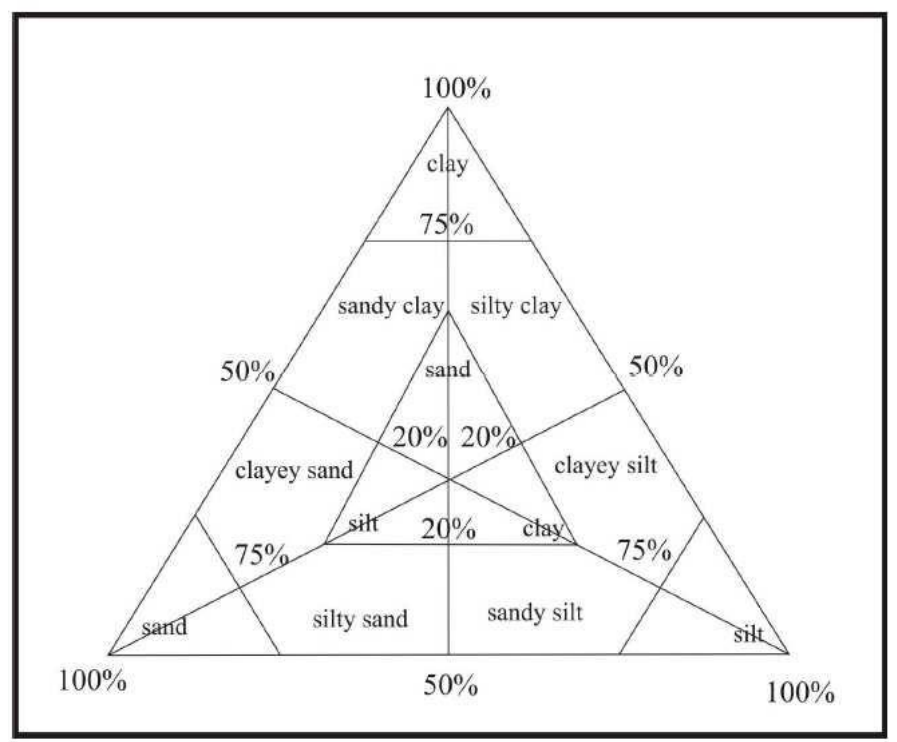

Gambar 2. Segitiga Shepard (Triapriyasen et al., 2016)

Analisa bahan organik dalam sedimen dilakukan dengan metode pengabuan (Arisa et al., 2014). Analisis kandungan Bahan Organik dilakukan berdasarkan prosedur AOAC. Dengan standar teknik pengabuan yang dilakukan di laboratorium. Terdapat 2 macam analisa yaitu analisa 
kadar air dan kadar abu. Analisa pertama adalah kadar air, botol timbang disterilisasi dengan dioven selama 1 jam lalu beratnya ditimbang. Botol diisi dengan sampel sebanyak $1 \mathrm{gr}$ lalu dioven selama 6 jam. Setelah selesai dioven, botol ditimbang. Kemudian kadar airnya dihitung dengan rumus:

$$
\text { Kadar Air }=\frac{(\text { botol kosong }+1 \mathrm{gr})-\text { botol setelah dioven }}{\text { berat sampel } * 100 \%}
$$

Analisa kedua yaitu kadar abu, Cp timbang disterilisasi dengan dioven selama 1 jam lalu beratnya ditimbang. Cp diisi dengan sampel sebanyak $1 \mathrm{gr}$. Sampel dimasukkan kedalam Tanur selama 6 jam dengan suhu $550^{\circ} \mathrm{C}$, setelah itu ditimbang. Kemudian kadar abunya dihitung dengan rumus:

$$
\text { Kadar Abu }=\frac{\text { berat setelah tanur }-c p \text { kosong }}{\text { berat sampel } * 100 \%}
$$

Kandungan Bahan Organik pada sampel akan didapatkan dengan menggunakan rumus:

$$
B O=\text { Kadar } B K-\text { Kadar } A b u
$$

Dimana Kadar BK memiliki rumus sebagai berikut:

$$
\text { Kadar BK }=100 \%-\text { Kadar Air }
$$

\section{HASIL DAN PEMBAHASAN}

Berdasarkan hasil analisa jenis sedimen di perairan Pantai Kartini, Jepara ini menunjukkan bahwa sedimen jenis pasir mendominasi lokasi penelitian dengan nilai berkisar $81 \%-96 \%$. Sedimen jenis pasir terdapat pada 3 stasiun pengamatan dengan prosentase rata-rata diatas $87,46 \%$, dimana yang tertinggi pada stasiun 2 sebesar 95,36\%. Hasil analisa 3 stasiun menunjukkan bahwa jenis sedimen didominasi oleh pasir, jenis sedimen yang mendekati daratan umumnya didominasi oleh jenis pasir tersebut (Arisa et al., 2014). Hasil analisa kandungan bahan organik yang terkandung pada sampel sedimen di perairan Pantai Kartini, Jepara memiliki nilai konsentrasi 5-14\%. Pada penelitian ini ditemukaan 2 (dua) kriteria prosentase kandungan bahan organik, yaitu rendah dengan kisaran 3,5-7\% dan sedang dengan kisaran 7-17\% (Reynold, 1971). Sedimen pasir sedikit mengandung bahan organik dikarenakan memiliki struktur butiran yang lebih besar dari jenis sedimen lanau, kerapatannya rendah, permeabilitas yang tinggi, dan mudah mengalami pencucian (akibat pasang surut), sehingga sulit untuk menyimpan bahan organik yang terlarut (Hakim et al., 2016). Bahan organik yang terlarut dalam perairan dengan proses fisika maupun kimia akan terendapkan di dasar perairan dan membentuk kandungan organik pada sedimen yang terdiri dari partikel-partikel hasil pecahan batuan dan potongan-potongan kulit serta sisa rangka organisme laut ataupun dari detritus organik daratan yang telah terangkut oleh air maupun angin dan terendapkan di dasar laut dalam kurun waktu yang cukup lama (Rustam et al., 2018). Hasil analisa sedimen dan bahan organik pada daerah penelitian terlihat pada Tabel 1. dan Gambar 3.

Berdasarkan prosentase kandungan bahan organik yang termasuk kedalam kriteria rendah terdapat pada Stasiun 2 yang berkisar antara 5,92-10,18\%. Stasiun tersebut terletak di daerah yang mendekati garis pantai dan memiliki jenis sedimen berupa pasir (sand). Pada daerah tersebut ukuran butir sedimen lebih besar dan kasar. Rendahnya prosentase kandungan bahan organik di Stasiun 2 kemungkinan bisa disebabkan oleh sedikitnya angkutan atau masukan material organik dari sungai. Adanya bebatuan di dekat pantai yang mana dapat menyebabkan aliran sungai terhambat, sehingga suplai material organik sedikit.

Stasiun 1 dan 3 memiliki prosentase kandungan bahan organik yang termasuk kedalam kriteria sedang. Pada stasiun ini didominasi dengan jenis sedimen pasir (sand). Namun, ukuran 
butir pasir lebih besar di Stasiun 2, dibandingkan dengan Stasiun 1 dan 3. Lokasi stasiun kriteria sedang ini terdapat di daerah yang sedikit lebih jauh dari garis pantai. Jumlah prosentase kandungan bahan organik pada kriteria sedang berkisar antara 7\% hingga 14\%. Stasiun 1 dan 3 merupakan sungai yang sudah tidak aktif, dimana kurang mendapat pengaruh dari arus namun berada dekat dengan vegetasi mangrove.

Tinggi konsentrasi bahan organik dipengaruhi oleh kedalaman perairan, selain itu juga lokasi pengukuran yang berada dekat dengan vegetasi mangrove serta aktivitas manusia di daerah pesisir tersebut. Kurangnya pengaruh dari arus juga dapat mempengaruhi tinggi konsentrasi bahan organik dimana bahan organik akan lebih cepat mengendap karena arus tidak mampu membawa lebih jauh menuju laut (Daulat et al., 2014). Terdapat hubungan antara kandungan bahan organik dengan ukuran partikel sedimen. Stasiun 1 dan 3 merupakan daerah menerima masukan dari pemukiman penduduk, tambak budidaya serta ditemukan vegetasi mangrove lebih banyak dari lokasi penelitian sehingga terjadi proses pemasukkan bahan organik tambahan ke dalam suatu perairan (Wahyuningrum et al., 2016). Sumber bahan organik dapat berasal dari daratan akibat limbah rumah tangga, pertanian, proses pembusukan organsime yang telah mati, perubahan metabolik ekstraseluler oleh algae, ekskresi zooplankton dan hewan lainnya (Nybakken, 1992). Sedimen yang letaknya lebih jauh dari lautan lepas dan terlindung dari pengaruh arus yang kuat serta banyak bahan organik dan detritus yang dibawa air sungai dan menumpuk di perairan, terutama pada saat arus melemah yang disebabkan oleh keberadaan kawasan mangrove memiliki ukuran yang lebih halus (Gemilang et al., 2017).

Tabel 1. Prosentase jenis sedimen dan bahan organik di Pantai Kartini, Jepara

\begin{tabular}{llcccc}
\hline & & \% Pasir & \% Lanau & \% Clay & \% Organik \\
\hline \multirow{4}{*}{ S1 } & Kisaran & $91,6-96$ & $3,99-10,97$ & $0,06-0,1$ & $10,9-13,3$ \\
& Rata rata & 92,33 & 7,60 & 0,07 & 11,58 \\
& SD & 2,41 & 2,40 & 0,01 & 0,98 \\
\hline \multirow{3}{*}{ S2 } & Kisaran & $93,5-96,9$ & $3,04-6,4$ & $0,01-0,08$ & $5,92-10,18$ \\
& Rata rata & 95,36 & 4,57 & 0,07 & 7,88 \\
& SD & 1,28 & 1,28 & 0,00 & 1,61 \\
\hline \multirow{3}{*}{ S 3 } & Kisaran & $81,4-92,9$ & $7,1-18,6$ & $0,007-0,14$ & $7,7-14$ \\
& Rata rata & 87,46 & 12,45 & 0,09 & 9,48 \\
& SD & 5,14 & 5,13 & 0,03 & 2,30 \\
\hline
\end{tabular}

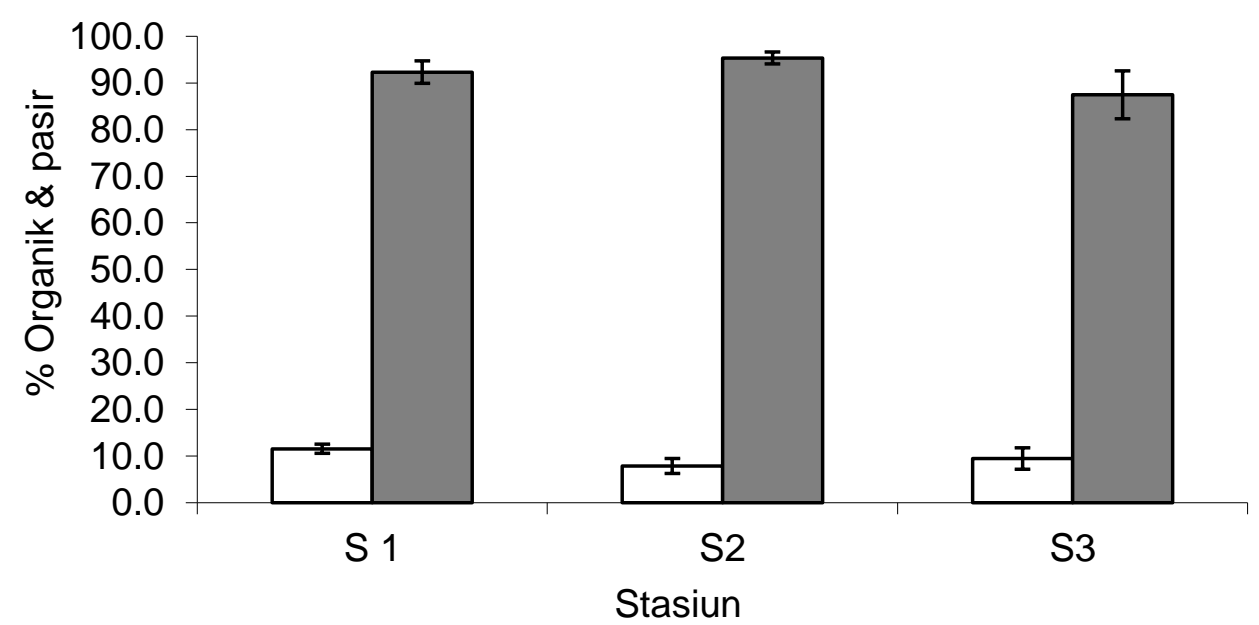

口\% Organik घ\% Pasir

Gambar 3. Rata-Rata Prosentase Pasir dan Bahan Organik di Perairan Pantai Kartini, Jepara 


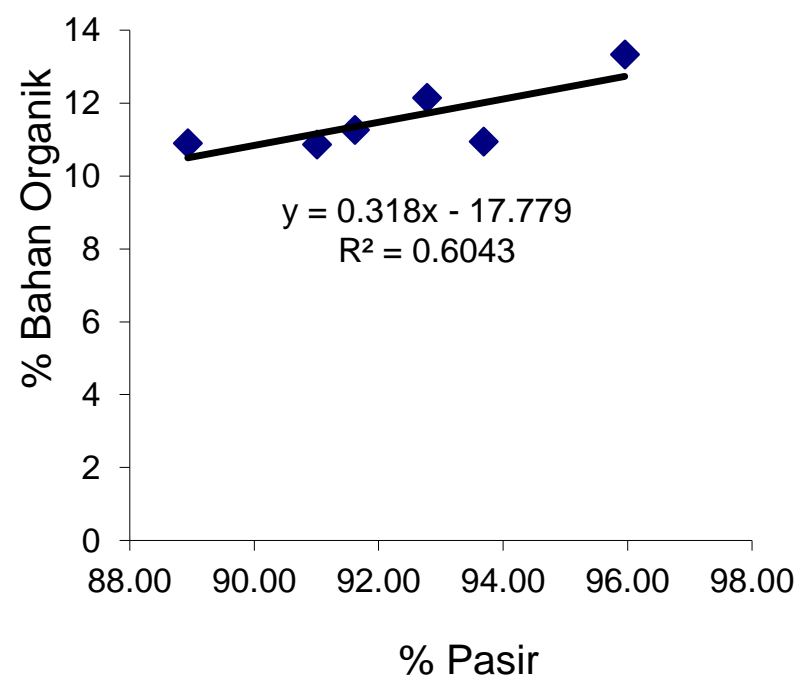

Stasiun 1

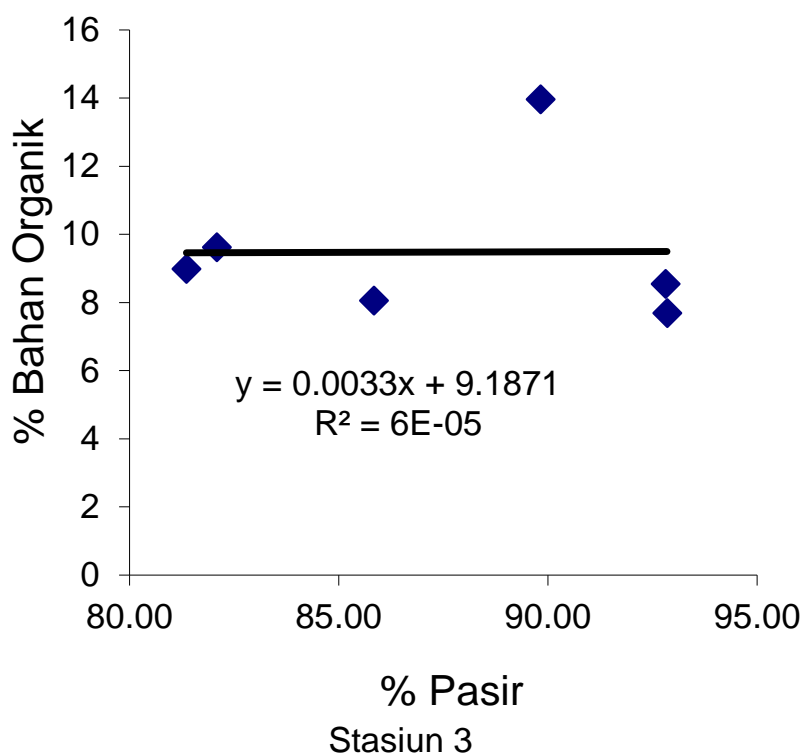

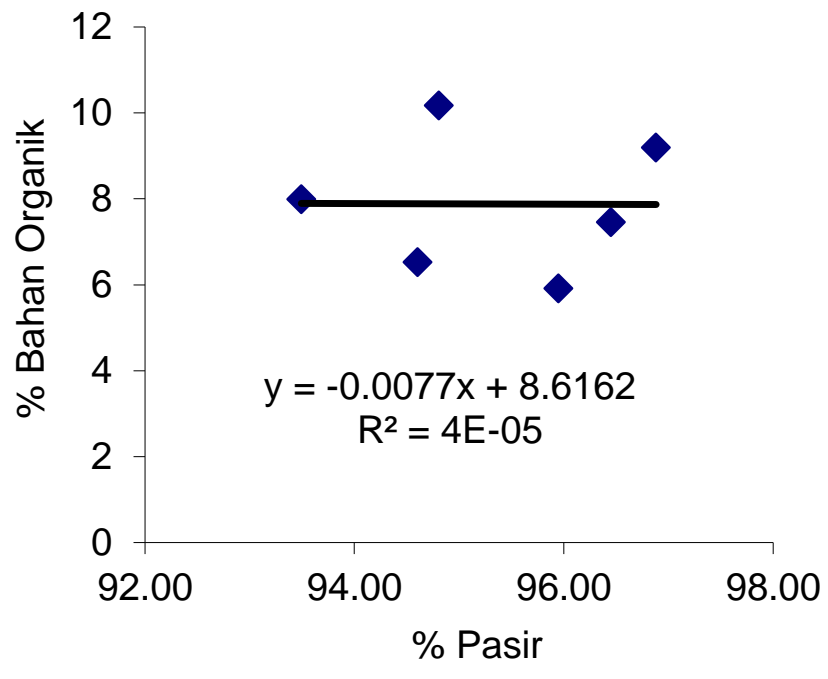

Stasiun 2

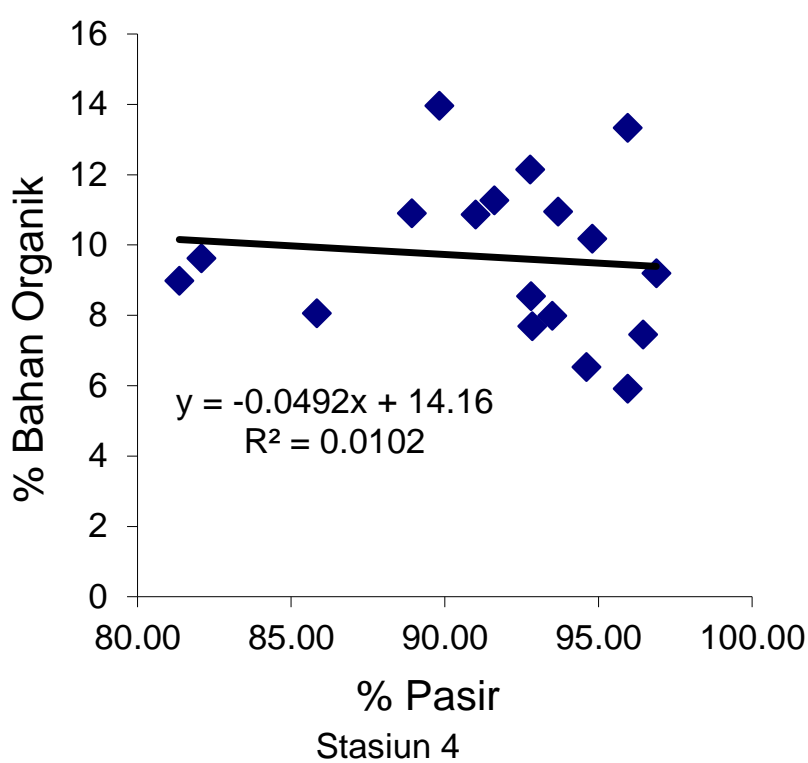

Gambar 4. Hubungan Bahan Organik dan Pasir

Hubungan pasir dan bahan organik pada Stasiun 1 membentuk garis linear yang naik (Gambar 4). Pada stasiun nilai $R^{2}=0,604$, maka dapat diartikan bahwa $60,4 \%$ besarnya kandungan bahan organik dipengaruhi oleh fraksi pasir, sedangkan 39,6\% sisanya dipengaruhi oleh fraksi lain (lanau maupun clay). Hal ini menunjukkan bahwa fraksi pasir pada Stasiun 1 berpengaruh terhadap kandungan bahan organik yang cukup besar. Sesuai pernyataan Pamuji et al. (2015), bahwa nilai $r$ dalam kisaran 0,6 sampai 0,79 membuktikan bahwa hubungan antara fraksi pasir dengan kandungan bahan organik terbilang kuat. Sedangkan pada Stasiun 2 dan 3, garis linear yang terbentuk cenderung turun dan konstan, ini berarti bahwa prosentase kandungan bahan organik yang terkandung dalam Stasiun 2 lebih rendah karena prosentase pasir yang lebih tinggi, lalu pada Stasiun 3 prosentase bahan organik lebih besar daripada pasir walaupun tidak terlalu signifikan. Dapat dilihat dari ketiga hubungan tersebut terdapat adanya pengaruh antara fraksi pasir dengan kandungan bahan organik dalam sedimen. Meskipun tidak menunjukkan hubungan positif nyata, namun variabel yang ada memiliki ketergantungan yang cukup kuat satu dengan yang lain serta faktor determinasi yang cukup berpengaruh.

Berdasarkan hasil analisa korelasi pasir dan bahan organik terhadap seluruh stasiun dapat dilihat pada Gambar 4, dimana dapat diketahui bahwa garis linear yang tercipta berbentuk 
menurun dan nilai $\mathrm{R}^{2}$ sebesar 0,010 , yang mana dapat dikatakan bahwa hubungan prosentase pasir dengan bahan organik yang terdapat dalam partikel pasir tersebut terbilang kecil. Hal tersebut dapat diartikan bahwa kandungan bahan organik pada sedimen pasir lebih sedikit. Sesuai dengan pernyataan Arisa et al. (2014) yang menyatakan bahwa partikel sedimen yang berukuran lebih kecil memiliki kemampuan untuk menjebak bahan organik lebih tinggi dibandingkan dengan partikel sedimen yang berukuran lebih besar. Menurut Choirudin et al. (2015) yang menyatakan bahwa sedimen yang halus prosentase bahan organik lebih tinggi daripada sedimen yang kasar, hal ini juga dipengaruhi oleh kondisi lingkungan, dimana lingkungan yang tenang memungkinkan pengendapan lumpur yang diikuti akumulasi bahan organik kedasar perairan, sedangkan pada sedimen yang kasar, kandungan bahan organiknya rendah karena partikel yang lebih halus tidak mengendap. Menurut Irham et al. (2020), bahwa substrat lumpur merupakan endapan yang dihasilkan dari pergerakan air laut dengan energi yang lemah. Partikel-partikel yang mengendap kebanyakan bersifat organik. Maka dari itu, pada stasiun penelitian yang memiliki jenis sedimen pasir kandungan bahan organiknya tidak sebanyak yang berada di sedimen lumpur atau sedimen yang lebih halus teksturnya. Menurut Taqwa et al. (2014), bahwa substrat pasir yang partikel dan pori-porinya lebih besar menyebabkan bahan organik mudah terbawa arus atau sulit mengendap, dibandingkan dengan substrat lumpur yang pori-porinya lebih rapat sehingga mudah mengendapkan bahan organik. Kandungan bahan organik dalam sedimen sangat berhubungan dengan jenis atau tekstur sedimen, tekstur yang berbeda mempunyai kandungan bahan organik yang berbeda pula.

\section{KESIMPULAN}

Perairan sekitar Pantai Kartini, Jepara memiliki jenis sedimen pasir (sand) dimana nilai ukuran butir tersebut adalah 81-96\% yang mana tergolong kasar. Kandungan Bahan Organik yang terdapat di perairan sekitar Pantai Kartini, Jepara memiliki konsentrasi sebesar $5-14 \%$ yang termasuk dalam kriteria rendah-sedang. Hubungan prosentase pasir dengan bahan organik yang terdapat dalam partikel pasir pada penelitian terbilang kecil atau rendah, dimana semakin besar prosentase pasir maka garis linearnya semakin menurun atau bahan organik yang terkandung di dalam partikel pasir sedikit.

\section{DAFTAR PUSTAKA}

Arisa, R.R.P., Kushartono, E.W. \& Atmodjo, W. 2014. Sebaran Sedimen dan Kandungan Bahan Organik pada Sedimen Dasar Perairan Pantai Slamaran Pekalongan. Journal of Marine Research, 3(3):342-350.

Bayhaqi, A. \& Dungga, C.M.A.. 2015. Distribusi Butiran Sedimen di Pantai Dalegan, Gresik, Jawa Timur. Jurnal Depik, 4(3):153-159.

Choirudin, I.R., Supardjo, M.N. \& Muskananfola, M.R. 2014. Studi Hubungan Kandungan Bahan Organik Sedimen dengan Kelimpahan Makrozoobenthos di Muara Sungai Wedung Kabupaten Demak. Diponegoro Journal of Maquares, 3(3):168-176.

Daulat, A., Kusumaningtyas, M.A., Adi, R.A. \& Pranowo, W.S.. 2014. Sebaran Kandungan $\mathrm{CO}_{2}$ Terlarut di Perairan Selatan Kepulauan Natuna. Jurnal Depik, 3(2):166-177.

Gemilang, W.A., Wisha, U.J. \& Kusumah, G. 2017. Distribusi Sedimen Dasar sebagai Identifikasi Erosi Pantai di Kecamatan Brebes Menggunakan Analisis Granulometri. Jurnal Kelautan, 10(1):54-66.

Hakim, M.A., Martuti, N.K.T. \& Irsadi, A. 2016. Estimasi Stok Karbon Mangrove di Dukuh Tapak Kelurahan Tugurejo Kota Semarang. Life Science, 5(2):87-94.

Handoyo, G. \& Suryoputro, A.A.D.. 2015. Kondisi Arus dan Gelombang pada Berbagai Kondisi Morfologi Pantai di Perairan Pantai Kendal Provinsi Jawa Tengah. Jurnal Kelautan Tropis, 18(1):33-37.

Irham, M., Adhla, S. \& Octavina, C. 2020. Analisis Kimia Sedimen di sekitar Ekosistem Mangrove Desa Lambadeuk, Peukan Bada, Aceh Besar. Jurnal Depik, 9(1):1-7.

Manengkey, H.W.K. 2010. Kandungan Bahan Organik pada Sedimen di Perairan Teluk Buyat dan sekitarnya. Jurnal Perikanan dan Kelautan Tropis, 6(3):114-119. 
Mushthofa, A., Muskananfola, M.R. \& Rudiyantim S. 2014. Analisis Struktur Komunitas Makrozoobenthos sebagai Bioindikator Kualitas Perairan Sungai Wedung Kabupaten Demak. Diponegoro Journal of Maquares, 3(1):81-88.

Nybakken, J.W. 1992. Biologi Laut Suatu Pendekatan Ekologi. Jakarta. Gramedia : 459 hal.

Pamuji, A., Muskananfola, M.R. \& A'in, C. 2015. Pengaruh Sedimentasi terhadap Kelimpahan Makrozoobenthos di Muara Sungau Betahwalang Kabupaten Demak. Jurnal Saintek Perikanan, 10 (2):129-135.

Rahmawati, W., Handoyo, G. \& Rochaddi, B. 2015. Kajian Elevasi Muka Air Laut di Perairan Pantai Kartini Jepara. Jurnal Oseanografi, 4(2):487-491.

Reynold, S.C. 1971. A Manual of Introductory Soil Science and Simple Soil Analysis Methods. South Pasific, Nouena New Caledonia.

Rustam, A., Adi, N.S., Mutikasari, E., Kepel, T.L. \& Kusumaningtyas, M.A. 2018. Karakteristik Sebaran Sedimen dan Laju Sedimentasi Perairan Teluk Banten. Jurnal Segara, 14(3):137144.

Taqwa, R.N., Muskananfola, M.R. \& Ruswahyuni. 2014. Studi Hubungan Substrat Dasar dan Kandungan Bahan Organik dalam Sedimen dengan Kelimpahan Hewan Makrobenthos di Muara Sungai Sayung Kabupaten Demak. Diponegoro Journal of Maquares, 3(1):125-133.

Triapriyasen, A., Muslim \& Suseno, H.. 2016. Analisis Jenis Ukuran Butir Sedimen di Perairan Teluk Jakarta. Jurnal Oseanografi, 5(3):309-316.

Usman, K.O. 2014. Analisis Sedimentasi pada Muara Sungai Komering Kota Palembang. Jurnal Teknik Sipil dan Lingkungan, 2(2):209-215.

Wahyuningrum, E.S., Muskananfola, M.R. \& Suryanto, A. 2016. Hubungan Tekstur Sedimen, Bahan Organik dengan Kelimpahan Biota Makrozoobentos di Perairan Delta Wulan, Kabupaten Demak. Diponegoro Journal of Maquares, 5(1):46-51. 